\title{
Short-term exposure to repeated chasing stress does not induce habituation in Senegalese sole, Solea senegalensis
}

Conde-Sieira, Marta; Valente, Luisa M.P. ; Hernandez-Perez, Juan; Soengas, José L.; Míguez, Jesús M.; Gesto, Manuel

\section{Published in:}

Aquaculture

Link to article, DOI:

10.1016/j.aquaculture.2018.01.003

Publication date:

2018

Document Version

Peer reviewed version

Link back to DTU Orbit

Citation (APA):

Conde-Sieira, M., Valente, L. M. P., Hernandez-Perez, J., Soengas, J. L., Míguez, J. M., \& Gesto, M. (2018). Short-term exposure to repeated chasing stress does not induce habituation in Senegalese sole, Solea senegalensis. Aquaculture, 487, 32-40. https://doi.org/10.1016/j.aquaculture.2018.01.003

\section{General rights}

Copyright and moral rights for the publications made accessible in the public portal are retained by the authors and/or other copyright owners and it is a condition of accessing publications that users recognise and abide by the legal requirements associated with these rights.

- Users may download and print one copy of any publication from the public portal for the purpose of private study or research.

- You may not further distribute the material or use it for any profit-making activity or commercial gain

- You may freely distribute the URL identifying the publication in the public portal 


\section{Accepted Manuscript}

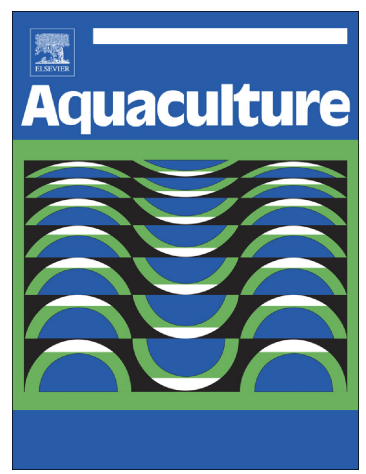

Marta Conde-Sieira, Luisa M.P. Valente, Juan Hernández-Pérez, José L. Soengas, Jesús M. Míguez, Manuel Gesto

PII: $\quad$ S0044-8486(17)32494-8

DOI: $\quad$ https://doi.org/10.1016/j.aquaculture.2018.01.003

Reference: $\quad$ AQUA 633005

To appear in: aquaculture

Received date: $\quad 29$ August 2017

Revised date: $\quad 14$ December 2017

Accepted date: $\quad 3$ January 2018

Please cite this article as: Marta Conde-Sieira, Luisa M.P. Valente, Juan Hernández-Pérez, José L. Soengas, Jesús M. Míguez, Manuel Gesto , Short-term exposure to repeated chasing stress does not induce habituation in Senegalese sole, Solea senegalensis. The address for the corresponding author was captured as affiliation for all authors. Please check if appropriate. Aqua(2017), https://doi.org/10.1016/j.aquaculture.2018.01.003

This is a PDF file of an unedited manuscript that has been accepted for publication. As a service to our customers we are providing this early version of the manuscript. The manuscript will undergo copyediting, typesetting, and review of the resulting proof before it is published in its final form. Please note that during the production process errors may be discovered which could affect the content, and all legal disclaimers that apply to the journal pertain. 


\title{
Short-term exposure to repeated chasing stress does not induce habituation in Senegalese sole, Solea senegalensis
}

\author{
Marta Conde-Sieira ${ }^{1,2}$, Luisa M.P. Valente ${ }^{2,3}$, Juan Hernández-Pérez ${ }^{1}$, José L. Soengas ${ }^{1}$, Jesús \\ M. Míguez ${ }^{1}$, Manuel Gesto ${ }^{1,4}$
}

${ }^{1}$ Laboratorio de Fisioloxía Animal, Departamento de Bioloxía Funcional e Ciencias da Saúde, Facultade de Bioloxía and Centro Singular de Investigación Mariña-ECIMAT, Universidade de Vigo, 36310, Vigo, Spain.

${ }^{2}$ CIMAR/CIIMAR, Centro Interdisciplinar de Investigação Marinha e Ambiental, Universidade do Porto, Av. General Norton de Matos s/n, 4050-208 Matosinhos, Portugal.

${ }^{3}$ ICBAS, Instituto de Ciências Biomédicas de Abel Salazar, Universidade do Porto, R. Jorge de Viterbo Ferreira 228, 4050-313 Porto, Portugal.

${ }^{4}$ Present Address: Section for Aquaculture, The North Sea Research Centre, DTU Aqua, Technical University of Denmark, Hirtshals, Denmark

Running title: Stress habituation in sole

\section{Corresponding author:}

Dr. Marta Conde Sieira

Laboratorio de Fisioloxía Animal

Facultade de Bioloxía

Universidade de Vigo

E-36310 Vigo

Spain

Tel. +34-986 812564

Fax +34-986 812556

E-mailmconde@uvigo.es 


\section{Abstract}

Animals can habituate to certain repeated stressors and reduce the physiological response that such stressor evoked initially. Studies related to stress habituation in fish are scarce and the available data differ depending on the species and on the type, duration and severity of the stressor. The main objective of this study was to investigate the stress response of juvenile Senegalese sole (Solea senegalensis) submitted to repeated chasing stress for 3 days previous to the experiment in order to evaluate the occurrence of habituation to those stress conditions in this fish species. Thus, five different experimental groups were evaluated: not stressed fish (control, C), fish stressed only on the experimental day (ST/naïve), and fish stressed on the experimental day and on the 3 previous days: during the day (ST/Dt), at night $(\mathrm{ST} / \mathrm{Nt})$ or both $(\mathrm{ST} / \mathrm{Dt}+\mathrm{Nt})$. Parameters related to primary and secondary responses to chasing were evaluated in plasma, liver and brain. Chasing in ST/naïve group induced incremented values of plasma cortisol, glucose and lactate but no changes in catecholamine levels compared to controls. In trained fish, higher cortisol but decreased glucose, lactate and catecholamine levels were observed after stress compared to controls and to ST/naïve groups. In the liver, stress did not induce any changes with respect to controls whereas ST/Dt and ST/Dt+Nt showed lower values of glucose and glycogen than stressed naïve fish. In the brain, ST/naïve group presented no significant changes in serotonergic activity. However, incremented serotonergic activity was detected in fish previously trained. Furthermore, dopaminergic activity decreased in diurnal trained and nocturnal trained groups with respect to ST/naïve fish. Crh expression in hypothalamus was higher in ST/naïve fish but not in fish submitted to repeated stress compared to controls. In summary, it seems that there was no habituation to the repeated acute stress protocol in Solea senegalensis in terms of serotonergic activity and cortisol release during the physiological stress response. However, the decreased levels of plasma catecholamines and energy metabolites, and of the hypothalamic crh mRNA abundance and dopaminergic activity, indicate a modulation of the stress response in trained fish. Altogether, the results suggest that either the chasing stressor was too strong or the training period too short for the animals to habituate, indicating that repeated chasing within short periods should be avoided when manipulating fish in order to keep proper welfare conditions in this species.

Key words: repeated stress; chasing stress; habituation; HPI axis; monoamines; Senegalese sole. 


\section{Introduction}

International concern about fish welfare is increasing and presently, the control of the stressors experienced by fish in aquaculture or research facilities is an important issue to be considered from both the legal and ethical points of view. Besides, uncontrolled stressors may also result in productivity losses in aquaculture. Nevertheless, different kind of stressors are inherent to the life in captivity and a research effort should be made to minimize the impact of different routine procedures on the health and welfare of the fish, especially when the stress suffered by the animals could become chronic.

It is known that animals, to certain extent, can habituate to relatively mild stressors in such a way that they present modified, most usually reduced physiological and behavioral responses to stressors that are repeated in time (Grissom and Bhatnagar, 2009; Nilsson et al., 2012; Rose and Rankin, 2001; Viblanc et al., 2012). Habituation has been traditionally considered a nonassociative form of learning, and it is believed to have strong evolutionary utility for the conservation of energy and resources by dampening responses to stressors that are not life-threatening (Grissom and Bhatnagar, 2009; Mc Carty, 2016; Nesse et al., 2010). Information about the ability of fish to habituate to repeated stressors is very scarce since most studies dealing with stress exposure in fish usually comprise laboratory-based trials in which the stressors are applied only once and in which the fish have no or little previous experience with the stressor. Inherent stressors to fish rearing facilities include handling, changes in water quality, tank cleaning, sizing, vaccination/treatment administration, among others. The repeated exposure to the same or different stressor could result in a situation of chronic stress that can become maladaptive for the fish (Wendelaar Bonga, 1997). However, little is known about the ability of the fish to habituate to those stressors. Any kind of habituation or sensitization would be of relevance to the assessment of the actual welfare status of the fish in a facility, since habituation ability is part of fish natural robustness against stress exposure (Noakes and Jones, 2012). Some data suggest that fish are able to habituate to certain stressors (Johansson et al., 2016; Madaro et al., 2016b) but not to others (Barcellos et al., 2006; Koakoski et al, 2013). The physiological capacity for habituation in fish seems to depend on the type of stressor, the severity and the species involved. It has been shown for example that the hypothalamus-pituitary-interrenal (HPI) axis response in Atlantic salmon was reduced upon exposure to a repeated stressor (5-min chasing, twice a day) for 5 days (Madaro et al., 2016b). 
The Senegalese sole, Solea senegalensis is a relatively new species in aquaculture and the knowledge regarding potential stressors and the species stress resilience is still limited when compared to other fish species such as salmonids. Recent research demonstrated that the HPI axis of S. senegalensis is sensitive to acute stressors such as handling, high stocking density, salinity changes, poor water quality or air exposure (Costas et al., 2008, 2011; Gesto et al., 2016; LópezOlmeda et al., 2013; López-Patiño et al., 2013; Weber et al., 2012; Wunderink et al., 2011;) but almost no information is available regarding the adaptability to repeated and chronic stressors in this species.

In the present study we evaluated the ability of the Senegalese sole to habituate to a chasing protocol after repeated exposure. Brain (serotonergic and dopaminergic activity in telencephalon and hypothalamus, hypothalamic $c r h$ and $c r h b p$ transcript levels), plasma stress markers (adrenaline, noradrenaline, cortisol, glucose and lactate levels) and liver metabolites (glucose, glycogen and lactate levels) were evaluated after a chasing protocol in fish that had been repeatedly exposed to the same stressor as well as in naïve fish. Since the stress sensitivity of the fish could vary depending on the moment of the day (López-Olmeda et al., 2013; Oliveira et al., 2013), repeated stress was applied during the day, during the night, or during day and night.

\section{Materials and Methods}

\subsection{Animals}

Senegalese sole obtained from a commercial fish farm (Aquacria Piscícolas, S.A., Aveiro, Portugal) were kept under quarantine conditions for a 3-week period. The fish were then individually weighed $(88.3 \pm 1.5 \mathrm{~g})$, measured and distributed (5 fish per tank) among 10 fiberglass rectangular tanks $(0.5 \mathrm{~m} \times 0.4 \mathrm{~m} \times 0.3 ; 60 \mathrm{~L})$ in a closed recirculation system. The system was

supplied with filtered and heated $\left(20.0 \pm 1.0{ }^{\circ} \mathrm{C}\right)$ seawater $(24 \mathrm{ppm})$ at a flow rate of $1.5 \mathrm{~L}^{\mathrm{min}}{ }^{-1}$. The daily water renovation of the system was set up at $20 \%$ to help keeping good standards in water quality. An artificial photoperiod of $12 \mathrm{~h}$ light:12 h dark was established. Fish were fed by hand once daily $(16.00 \mathrm{~h})$ to satiety with a diet manufactured by Sparos, Portugal (proximate feed analysis was $57.9 \%$ crude protein, $0.8 \%$ fibre, $15.5 \%$ starch, $8.6 \%$ crude fat, and $8.5 \%$ ash; 20.3 $\mathrm{MJ} / \mathrm{kg}$ of feed). The experiment was directed by trained scientists (following category C FELASA recommendations) and conducted according to the European guidelines on protection of animals used for scientific purposes (directive 2010/63/EU). 


\subsection{Experimental design}

Following a 2-week acclimation period and during the 3 previous days of the experiment, fish of different tanks were stressed by chasing (forcing the fish to move with a net during $5 \mathrm{~min}$ ) at different times and per duplicated tanks, according to the following experimental groups (Fig. 1): Diurnal trained fish (ST/Dt) composed by fish stressed during the day (at 10.00, 12.00 and 14.00 hours); Nocturnal trained fish (ST/Nt) including fish stressed during the night (18.00, 20.00 and 22.00 hours); and diurnal and nocturnal trained fish $(\mathrm{ST} / \mathrm{Dt}+\mathrm{Nt})$ with fish stressed by chasing during whole day $(10.00,12.00,14.00,18.00,20.00$ and 22.00 hours $)$. On the day of the experiment, $24 \mathrm{~h}$ fasted fish from the different experimental tanks were stressed by chasing them with a dip net during 5 min. Moreover, two additional experimental groups were added: a control group (Control) consisting of undisturbed fish and a stressed group (ST/naïve) including naïve fish just exposed to the stressor the day of sampling. On the sampling day, all groups except the controls were submitted to a 5 min-chasing protocol. Thirty minutes after stress, fish were removed from their holding tanks, anesthetized (175 mg/L MS222) and sampled (5 fish per tank, in duplicate); netting was performed by experienced staff in a gentle way. Samples of blood, hypothalamus and telencephalon were removed firstly and then samples of liver were taken, lasting around $15 \mathrm{~min}$ for sampling each experimental tank. Tissue samples were immediately frozen on dry ice and stored at $-80{ }^{\circ} \mathrm{C}$ until further analyses. Plasma samples were obtained after blood centrifugation (9000 rpm, $10 \mathrm{~min}$ ), then deproteinized (using 0.6 M perchloric acid) and neutralized (using $1 \mathrm{M}$ potassium bicarbonate) before storage at $-80^{\circ} \mathrm{C}$ until analysis.

\subsection{Analysis}

\subsubsection{Plasma stress markers}

Plasma cortisol levels were quantified by a commercial ELISA kit (Cayman Europe, Estonia). Plasma glucose and lactate levels were quantified by means of commercial colorimetric kits (Biomérieux, France, and Spinreact, Spain; respectively).

The levels of plasma catecholamines (adrenaline and noradrenaline) were determined as previously described (Gesto et al., 2013).

\subsubsection{Metabolites in liver}


At the time of sampling a piece of about $75 \mathrm{mg}$ was dissected out from each fish liver. These pieces were immediately homogenized by ultrasonic disruption with 5.5 vols. of ice-cooled $0.6 \mathrm{M}$ perchloric acid, and neutralized (using $1 \mathrm{M}$ potassium bicarbonate). The homogenate was centrifuged (10,000 X g, $4 \mathrm{~min})$ and the resulting supernatant was immediately frozen on dry ice and stored at $-80^{\circ} \mathrm{C}$ until analysis. Liver glycogen levels were assessed using the method of Keppler and Decker (1974) and glucose obtained after glycogen breakdown (after subtracting free glucose levels) was determined with a commercial kit (Biomérieux, Spain). Hepatic lactate levels were determined with a commercial colorimetric kit (Spinreact, Spain).

\subsubsection{Brain monoamines}

The concentration of serotonin (5HT) and its main metabolite 5-hydroxyindole-3-acetic-acid (5HIAA), as well as dopamine (DA) and its main metabolite 3,4-dihydroxyphenylacetic-acid (DOPAC) were measured by means of HPLC with electrochemical detection as described previously (Gesto et al., 2016; López-Patiño et al., 2013). Tissues were weighed and homogenized by ultrasonic disruption in $0.5 \mathrm{ml}$ of the HPLC mobile phase. Homogenates were centrifuged $(16,000 \times \mathrm{g}, 10 \mathrm{~min})$ and supernatants were further diluted with mobile phase prior to HPLC analysis. Data obtained were normalized to homogenate protein content. Protein was assayed in triplicate in homogenates using microplates according to the bicinchoninic acid method (Smith et al., 1985) using bovine serum albumin (Sigma) as standard.

\subsection{4 mRNA abundance analysis by real-time quantitative RT-PCR}

Total RNA was extracted from hypothalamus samples (approx. $20 \mathrm{mg}$ ) using Trizol reagent (Life Technologies, NY, USA), following manufacturer's instructions, and RNA quantity and quality was evaluated by spectrophotometry (NanoDrop 2000, Thermo Fisher Scientific). Two $\mu \mathrm{g}$ of total RNA were reverse transcribed into cDNA using Superscript II reverse transcriptase (Promega, Madison, Wi, USA) and random hexaprimers (Promega). Gene expression levels were determined by real-time quantitative RT-PCR (q-PCR) using the iCycler iQ (BIO-RAD, Hercules, CA, USA). Analyses were performed on $5 \mu 1$ of diluted (1/50) cDNA using the MAXIMA SYBR Green qPCR Mastermix (Life Technologies), in a total PCR reaction volume of $15 \mu$, containing $120 \mathrm{nM}$ of each primer. Sequences of the forward and reverse primers used for the two gene expression assay are shown in Table 1. Relative quantification of the target genes was done using ubiquitin $(u b q)$ as reference gene (Infante et al., 2008). Thermal cycling was initiated with 
incubation at $95^{\circ} \mathrm{C}$ for 2 min using hot-start iTaq DNA polymerase activation; 35 steps of qPCR were performed, each one consisting of heating at $95^{\circ} \mathrm{C}$ for $15 \mathrm{~s}, 30 \mathrm{~s}$ at each specific annealing temperature (Table 1) and $30 \mathrm{~s}$ at $72{ }^{\circ} \mathrm{C}$. Following the final PCR cycle, melting curves were systematically monitored (temperature gradient at $0.5^{\circ} \mathrm{C} / \mathrm{s}$ from 55 to $94^{\circ} \mathrm{C}$ ) to ensure specificity of the amplification. Samples without reverse transcriptase and samples without cDNA were run as negative controls, which were indeed negative. Relative expression of the target genes was calculated using the delta-delta CT method (2- $\Delta \Delta \mathrm{CT})$, following Pffafl (2001).

\subsection{Statistics}

All results are expressed as mean \pm SEM. Statistical differences were assessed with a one-way ANOVA with experimental group (Control, ST/naïve, ST/Dt, ST/Nt and ST/Dt+Nt) as main factor. Only in those cases where a significant effect was noted within a factor, post-hoc comparisons were carried out by a Student-Newman-Keuls test, and differences were considered statistically significant at $\mathrm{P}<0.05$. When necessary data (cortisol, glucose and lactate in plasma) were $\log$ transformed to fulfill the conditions of the analysis of variance.

\section{Results}

\subsection{Plasma levels of stress markers}

Plasma levels of cortisol, glucose and lactate are presented in Fig. 2. The levels of these metabolites were higher in stressed fish (ST/naïve) compared to controls, with significant differences for cortisol $(P=0.014)$ and lactate $(P=0.042)$. Cortisol levels in trained fish showed higher values than controls in all groups $-\mathrm{ST} / \mathrm{Dt}(\mathrm{P}>0.001), \mathrm{ST} / \mathrm{Nt}(\mathrm{P}=0.001)$ and ST/Dt+Nt $(\mathrm{P}=$ 0.001)- and were also higher than $S T /$ naïve group in the case of ST/Dt fish $(\mathrm{P}=0.015)$. However, glucose levels were significant lower in ST/Dt, and ST/Dt+Nt compared to ST/naïve group (P < 0.001). In the case of lactate levels in plasma, the three trained groups showed decreased levels compared to controls and naïve fish $(\mathrm{P}<0.001)$.

Regarding catecholamine levels in plasma (Fig.3), they were lower in fish submitted to a reiterative stress compared to controls (in the case of noradrenaline; $\mathrm{P}=0.012$ ) and also compared to ST/naïve group in the case of adrenaline in ST/Dt and ST/Dt+Nt groups $(\mathrm{P}=0.003)$.

\subsection{Metabolite levels in liver}


The levels of glucose, glycogen and lactate in liver are presented in Fig.4. Single stress (ST/naïve) did not induce significant changes in any hepatic metabolite compared to controls. Repeated stress induced lower levels of glucose in ST/Dt and ST/Dt+Nt groups and glycogen in $\mathrm{ST} / \mathrm{Dt}+\mathrm{Nt}$ group compared to ST/naïve fish. In the case of lactate, no significant changes were detected in any experimental group.

\subsection{Brain monoamines}

The levels of monoamines related to dopaminergic and serotonergic system in hypothalamus are presented in Fig.5. DOPAC levels and the ratio DOPAC/DA levels were lower in ST/Dt and ST/Nt groups compared to ST/naïve and ST/Dt+Nt. No changes were found for DA. Levels of 5HIAA were higher than controls in all trained groups, and compared with ST/naïve group in the case of ST/Dt and ST/Dt+Nt, which also presented elevated values of serotonergic ratio (5HIAA/5HT) compared with control group.

In telencephalon (Fig.6), monoamines related to dopaminergic system did not display significant changes in any parameter. However, 5HIAA levels were higher in all stressed groups with respect to control, except for nocturnal trained fish $(\mathrm{ST} / \mathrm{Nt})$, and serotonergic ratio (5HIAA/5HT) was higher in ST/Dt and ST/Dt+Nt groups compared to controls.

\section{4. mRNA abundance}

Relative abundance of mRNA of $c r h$ and $c r h b p$ (Fig.7) was higher in single stressed fish (ST/naïve) with respect to the other experimental groups although significant changes were only observed in the case of $\mathrm{crh}$.

\section{Discussion}

In different animals, the magnitude of the response of the HPA/HPI neuroendocrine axis has been shown to decrease after repeated exposure to certain stressors, resulting in a lower release of corticosteroids into the blood by the adrenal cortex/interrenal cells. Therefore, blood corticosteroid levels are often used to assess habituation in vertebrates (Grissom and Bhatnagar, 2009; Mc Carty, 2016). However, caution should be taken when interpreting such attenuation as a habituation to the stressor, since other factors could be involved in a reduced hormonal response to stress (Cyr and Romero, 2009). In the present study, a set of different stress markers at different levels of the neuroendocrine cascade were evaluated to have a clear view of the stress status of the fish. 
The available literature on the habituation of fish to stressors is very scarce. Nevertheless, it has been shown that the corticosteroid response to stress in fish is often reduced after repeated exposure to a stressor (Fast et al., 2008; Jentoft et al., 2005; Madaro et al., 2016b; Nilsson et al., 2012). For example, Madaro and collaborators (2016b) showed that Atlantic salmon parr and postsmolts showed an attenuated cortisol response to a chasing protocol after being exposed just for a few days to the same stressor. This is not always the case, however, and in other studies with fish submitted to repeated stressors, the physiological response to stress after repeated or prolonged exposure was not reduced (Koakoski et al., 2013; Madaro et al., 2016a; Mugnier et al., 1998), suggesting that the habituation to stressors is dependent on fish species, and on stressor nature, severity, duration and timing. In our study, the elevated levels of cortisol observed after chasing stress in the different groups suggest that the fish did not habituate to the chasing after several repeated exposures in the time frame of 84 hours. Fish exposed repeatedly to chasing showed higher cortisol levels after a new chasing protocol when compared to naïve fish. A similar increase in plasma levels of cortisol after repeated stress was observed before in another flatfish species, the turbot (Mugnier et al., 1998). This may indicate that the fish were still not recovered from the previous chasing protocol and the cortisol response was mounted over that of the previous stress. In this regard, it is known that the dynamics of the stress response in the sole is slower than in other fish species such as rainbow trout (Gesto et al., 2013; 2016). Accordingly, in a previous study it was shown that, after a similar stressor to that applied here, S. senegalensis individuals needed more than 6 hours to recover basal values for cortisol and other stress markers (Gesto et al., 2016). In the current study, even when the chasing protocol before sampling was applied at least 14 hours after the previous stressor, we cannot discard the possibility that the repeated exposure had induced a longer-lasting physiological response. Plasma levels of other stress markers (glucose, lactate) usually follow a similar trend than cortisol after an acute stressor in fish (Wendelaar Bonga, 1997). Those increases usually occur due to cortisol and catecholamine actions on fish glucose metabolism, together with the increase in muscular activity upon exposure to a physical stressor. In this case, fish exposed to chasing stress for the first time, developed the usual increase in levels of plasma glucose and lactate. However, post-stress glucose levels were lower in fish repeatedly exposed to stress than in naïve fish. The reason for this is not known but it could relate to the inability of the fish to maintain the same levels of glucose in the blood due to the repeated mobilization of glucose. However, liver glycogen data do not support this hypothesis, since glycogen levels were not reduced in the ST/Dt and the ST/Nt groups, indicating that these fish were 
able to keep the elevated metabolite demand associated with stress. Therefore, a more plausible explanation for the reduced levels of plasma glucose in the repeatedly stressed fish could rely on the reduced catecholamine levels as discussed later. Post-stress lactate levels usually increase after acute stress in fish, partly because of a typical stress-induced increase in activity leading to a higher degree of anaerobic glycogenolysis (Van Ham et al., 2003). In this study, similarly to what happened with plasma glucose levels, post-stress lactate levels were lower in fish exposed repeatedly to stress than in naïve fish. Again, this was unlikely a consequence of the inability to maintain the same level of energy metabolites in the blood after repeated exposure to chasing. In this case, the observed reduced levels of lactate could be also explained by a reduced behavioral response after repeated exposure to the chasing protocol. Even considering that the swimming activity was not evaluated in this study, an evident alteration of the post-stress behavior was observed in the fish submitted to repeated stress: fish submitted for the first times to the stressor generally displayed a prompt escaping behavior. However, during the last exposures to the chasing protocol, the fish were barely moving during the chasing protocol. The reason of this behavioral inhibition is not known, but the reduced swimming activity could at least partly explain the reduced lactate levels in the repeatedly stressed groups. A role of plasma catecholamines and brain monoamines on this behavioral response cannot be discarded and will be commented later.

One of the fastest components of the fish stress response is the release of catecholamines from the chromaffin cells in the head kidney as a result of the stress-induced activation of the brainsympathetic nervous system- chromaffin cells axis (Wendelaar Bonga, 1997). In teleost fish, as in other vertebrates, the plasma levels of catecholamines increase rapidly after acute stress and also recover relatively fast when the stressor is no longer present (Gesto et al., 2013). The release of adrenaline and noradrenaline is species- and stressor dependent (Wendelaar Bonga, 1997) and in this regard, flatfishes are a special case among teleosts: they seem to lack adrenergic cardiac innervation (Donald and Campbell, 1982; Mendonça and Gamperl, 2009) and have a limited humoral adrenergic response to stress (Mendonça and Gamperl, 2009; Milligan and Wood, 1987). Thus, flatfish generally show post-stress plasma catecholamines levels that are much lower than in other teleosts such as rainbow trout (Gesto et al., 2013; Mendonça and Gamperl, 2009; Milligan and Wood, 1987). To the author's knowledge, the present study is the first report for plasma catecholamine levels in $S$. senegalensis, and they have been found to be very similar to those reported in other flatfish species (Mendonça and Gamperl, 2009). However, we were not able to detect any stress-induced effect on plasma catecholamine levels in naïve fish exposed to the chasing 
stress for the first time, compared to controls. This apparent lack of catecholaminergic response to stress could be the result of our sampling protocol: plasma catecholamines increase in a matter of seconds after stress in fish (Fabbri et al., 1998; Gesto et al., 2013) and, because of the time needed to net and anesthetize the fish, the levels observed in our control group were likely higher than those corresponding to the basal, not manipulated state. Interestingly, the levels of both noradrenaline and adrenaline were lower in all groups exposed to repeated stress than in the control group. This could be indicative of a lower release of catecholamines after repeated stress exposure, suggesting that the response of the brain-sympathetic-chromaffin axis was attenuated in those trained groups, which in turn points to a certain degree of habituation or modulation of this axis to the stressor. Furthermore, reduced catecholaminergic activation may well be the cause of the observed reduced levels of glucose and lactate in those groups, since catecholamines have a primordial role in mobilizing energy metabolites from glycogen stores in vertebrates (Fabbri et al., 1998; Wendelaar Bonga, 1997). In agreement, studies in rats indicate that plasma catecholamines decrease after chronic immobilization stress (Mc Carty, 2016).

A hepatic glycogen reduction associated with stressful conditions has been reported in fish (Conde-Sieira et al., 2014; Sangiao-Alvarellos et al., 2005; Vijayan et al., 1990). In Senegalese sole, the effect of stress on liver parameters differs among the available studies. In most available studies a decrease in the levels of glucose and glycogen was observed (Arjona et al., 2009; Costas et al., 2011, López-Patiño et al., 2013), though no changes occurred in others (López-Patiño et al., 2013). In the present study, metabolite levels in liver did not suffer significant changes in naïve fish submitted to chasing. However, fish submitted to reiterative stress (ST/Dt and ST/Dt+Nt) presented lower hepatic glucose levels than naïve fish, similarly to what was observed for plasma glucose. Furthermore, in $\mathrm{ST} / \mathrm{Dt}+\mathrm{Nt}$ group this decrease was significant probably because this group experienced the double of stress events. Taken into account that the glycogen reserves only decreased in the ST/Dt+Nt group, the decrease in the liver glucose levels, at least in the ST/Dt group, seem to relate to a lower glucose mobilization due to the lower levels of catecholamines, as commented before.

Another of the first components of the vertebrate response to stress is an increase of the activity of monoaminergic neurons in certain parts of the brain, which has been suggested to be part of the mechanism in charge of stress recognition and of the initiation of the stress response (Gesto et al., 2013; Lim et al., 2013; Winberg and Nilsson, 1993). The ratio between levels of 5HIAA and $5 \mathrm{HT}$, used as an indirect estimator of the serotonergic activity (Winberg and Nilsson, 1993), is 
consistently increased after exposure to different types of stress in fish (Conde-Sieira et al., 2014; Gesto et al., 2013; 2015; 2016; Øverli et al., 2001; Winberg and Nilsson, 1993). In this study, poststress serotonergic activity in telencephalon and hypothalamus of the $S$. senegalensis groups exposed to repeated stress were generally higher than in control fish, and tended to be also higher than in naïve fish, especially in the case of the fish submitted to the chasing stress during day and night. This data, similarly to what was shown by plasma cortisol levels, show that fish were increasingly affected by the repeated chasing protocols, and therefore are also in support of a lack of habituation of the fish to the chasing stressor in the time frame used in this experiment. On the other hand, the role of the dopaminergic system in the development of the stress response is not clear (Gesto et al., 2015), but it has been related to aggressiveness modulation in fish submitted to social stress in an antagonist manner to the serotonergic system (Gesto et al., 2015; Summers and Winberg, 2006). In the present study, the hypothalamus showed lower dopaminergic activity in ST/Dt and ST/Nt than naïve fish suggesting that dopaminergic system can be modulated in this tissue when a repeated stress protocol is applied. However, no changes in dopaminergic parameters were observed in the telencephalon after prolonged stress, which is in agreement with previous studies (Gesto et al., 2015). These data reflect the neural plasticity of the different brain areas, which is believed to be of relevance in the processes of learning (Johansen et al., 2012; Sorensen et al, 2013).

It has been described in fish, as in mammals, that brain monoamine neurotransmitters (DA, NA and 5HT) as well as neuropeptides like CRH mediate the biochemical switching in promoting adaptive behavioral stress responses (Sorensen et al., 2013; Winberg and Nilsson, 1993). Thus, the brain serotonergic system appears to inhibit aggression and spontaneous locomotor activity in fish whereas the dopaminergic system acts in the opposite way (Winberg and Nilsson, 1993). These associations are also reflected in the results here presented on the fish locomotor activity and monoaminergic activity. The corticotropin releasing hormone plays a key role in the regulation of the physiological response to stress in vertebrates (Alderman et al., 2008) and forebrain crh mRNA abundance has been shown to increase upon exposure to acute stress in fish (Huising et al. 2007; Manuel et al. 2014a), and in S. senegalensis in particular (Doyon et al., 2005; Gesto et al., 2016; Wunderink et al., 2011). The binding protein for CRH-related peptides, CRH-BP, modulates CRH actions in vertebrates. Its functions in fish are not well known, but its expression is mostly restricted to the CNS (Alderman et al., 2008) and has been suggested to have a modulatory role in the fish response to acute stress but not to chronic stress (Wunderink et al., 2011). In our study, as expected, 
the stress protocol also induced an increase in the mRNA abundance of $c r h$ in the hypothalamus of naïve fish. However, the post-stress levels of $\mathrm{CRH}$ transcripts in the three experimental groups exposed to repeated stress were lower and similar to those found in control fish. The downregulation of the mRNA abundance of crh could be part of a negative feedback mechanism involving cortisol action at the level of CNS in the repeatedly stressed fish. Previous studies with trout indicate that although cortisol levels remained elevated after a prolonged social stress, crh mRNA abundance in the preoptic area recovered basal levels in a few days under stress (Hostetler et al., 2013). Accordingly, in mammals unaltered levels of crh mRNA abundance after a repeated stress protocol were also observed, suggesting that crh mRNA abundance can habituate to a repeated and predictable stress (Pinnock and Herbet, 2001).

Finally, it is also worth to note that fish trained only during the night showed in several parameters (circulating levels of glucose and adrenaline, hepatic levels of glucose and 5HIAA levels and 5HIAA/5HT ratio in hypothalamus and telencephalon) no significant changes compared to naïves in contrast to the other trained groups. These results suggest that circadian processes could be affecting the stress response and/or the habituation capacity of the fish, suggesting the presence of a lower neural plasticity during the night. In accordance with this, it has been reported in fish that stress response show day-night differences (Landford, 2003; Manuel et al., 2014b, 2016). In Senegalese sole, it has also been reported that the HPI axis response under acute stress is higher during the night (López-Olmeda et al., 2013).

\section{Conclusions}

Altogether, the plasma cortisol and brain serotonergic data suggest that the fish were not habituated to the stress and that the repeated stressor was too strong and/or the training period too short for the fish to be able to adapt and reduce their physiological response in order to save energy resources. However, in spite of the lack of an attenuated HPI response to stress, some mechanisms seemed to be operative to at least reduce the behavioral response to stress. Accordingly, the trained fish showed lower post-stress levels of CRH, catecholamines, glucose and lactate, and an evident inhibition of the dopaminergic activity and behavioral response to the stressor after three days of repeated exposure. Based on that, it seems that both neuroendocrine axes involved in the fish stress response, the HPI axis and the brain-sympathetic-chromaffin axis, may response differently in terms of speed and degree of habituation to a repeated stressor, as has been observed in rats (De Boer et al., 1989, 1990). 


\section{Acknowledgements}

This research was partially supported by the Strategic Funding UID/Multi/04423/2013 through national funds provided by FCT - Foundation for Science and Technology and European Regional Development Fund (ERDF), in the framework of the programme PT2020 to L.M.P.V, and by research a grant from Spanish Agencia Estatal de Investigación and European Fund for Regional Development (AGL 2016-74857-C3-1-R and FEDER) to J.L.S. M.C-S. is supported by a postdoctoral grant from Xunta de Galicia (Plan I2C). There are no conflicts of interest in connection with the present study. 


\section{References}

Alderman, S.L., Raine, J.C., Bernier, N.J., 2008. Distribution and regional stressor-induced regulation of corticotrophin-releasing factor binding protein in rainbow trout (Oncorhynchus mykiss). J. Neuroendocrinol. 20, 347-358. doi:10.1111/j.1365-2826.2008.01655.x.

Arjona, F.J., Vargas-Chacoff, L., Ruiz-Jarabo, I., Gonçalves, O., Páscoa, I., Martín del Río, M.P., Mancera, J.M., 2009. Tertiary stress responses in Senegalese sole (Solea senegalensis Kaup, 1858) to osmotic challenge: implications for osmoregulation, energy metabolism and growth. Aquaculture 287, 419-426. doi: 10.1016/j.aquaculture.2008.10.047

Barcellos, L.J.G., Kreutz, L.C., Quevedo, R.M., 2006. Previous chronic stress does not alter the cortisol response to an additional acute stressor in jundiá (Rhamdia quelen, Quoy and Gaimard) fingerlings. Aquaculture 253, 317-321. doi:10.1016/j.aquaculture.2005.05.035.

Conde-Sieira, M., Muñoz, J.L.P., López-Patiño, M.A., Gesto, M., Soengas, J.L., Míguez, J.M., 2014. Oral administration of melatonin counteracts several of the effects of chronic stress in rainbow trout. Domest. Anim. Endocrinol. 46, 26-36. doi:10.1016/j.domaniend.2013.10.001.

Costas, B., Aragão, C., Mancera, J.M., Dinis, M.T., Conceição, L.E.C., 2008. High stocking density induces crowding stress and affects amino acid metabolism in Senegalese sole Solea senegalensis (Kaup 1858) juveniles. Aquac. Res. 39, 1-9. doi:10.1111/j.13652109.2007.01845.x.

Costas, B., Conceição, L.E.C., Aragão, C., Martos, J.A., Ruiz-Jarabo, I., Mancera, J.M., Afonso, A., 2011. Physiological responses of Senegalese sole (Solea senegalensis Kaup, 1858) after stress challenge: Effects on non-specific immune parameters, plasma free amino acids and energy metabolism. Aquaculture 316, 68-76. doi:10.1016/j.aquaculture.2011.03.011.

Cyr, N.E., Romero, L.M., 2009. Identifying hormonal habituation in field studies of stress. Gen. Comp. Endocrinol. 161, 295-303. doi:10.1016/j.ygcen.2009.02.001.

De Boer, S.F., Koopmans, S.J., Slangen, J.L., Van Der Gugten, J., 1990. Plasma catecholamine, corticosterone and glucose responses to repeated stress in rats: Effect of interstressor interval length. Physiol. Behav. 47, 1117-1124. doi:10.1016/0031-9384(90)90361-7.

De Boer, S.F., Van Der Gugten, J., Slangen, J.L., 1989. Plasma catecholamine and corticosterone responses to predictable and unpredictable noise stress in rats. Physiol. Behav. 45, 789-795. doi:10.1016/0031-9384(89)90296-5. 
Donald, J., Campbell, G., 1982. A comparative study of the adrenergic innervation of the teleost heart. J. Comp. Physiol. 147, 85-91. doi:10.1007/BF00689295.

Doyon, C., Trudeau, V.L., Moon, T.W., 2005. Stress elevates corticotropin-releasing factor (CRF) and CRF-binding protein mRNA levels in rainbow trout (Oncorhynchus mykiss). J. Endocrinol. 186, 123-130. doi:10.1677/joe.1.06142.

Fabbri, E., Capuzzo, A., Moon, T.W., 1998. The role of circulating catecholamines in the regulation of fish metabolism: An overview. Comp. Biochem. Physiol. - C Pharmacol. Toxicol. Endocrinol. 120, 177-192. doi:10.1016/S0742-8413(98)10017-8.

Fast, M.D., Hosoya, S., Johnson, S.C., Afonso, L.O.B., 2008. Cortisol response and immune-related effects of Atlantic salmon (Salmo salar Linnaeus) subjected to short- and long-term stress. Fish Shellfish Immunol. 24, 194-204. doi:10.1016/j.fsi.2007.10.009.

Gesto, M., Álvarez-Otero, R., Conde-Sieira, M., Otero-Rodiño, C., Usandizaga, S., Soengas, J.L., Míguez, J.M., López-Patiño, M.A., 2016. A simple melatonin treatment protocol attenuates the response to acute stress in the sole Solea senegalensis. Aquaculture 452, 272-282. doi:10.1016/j.aquaculture.2015.11.006.

Gesto, M., López-Patiño, M.A., Hernández, J., Soengas, J.L., Míguez, J.M., 2015. Gradation of the stress response in rainbow trout exposed to stressors of different severity: the role of brain serotonergic and dopaminergic systems. J. Neuroendocrinol. 27, 131-41. doi:10.1111/jne.12248.

Gesto, M., López-Patiño, M.A., Hernández, J., Soengas, J.L., Míguez, J.M., 2013. The response of brain serotonergic and dopaminergic systems to an acute stressor in rainbow trout: a time course study. J. Exp. Biol. 216, 4435-4442. doi:10.1242/jeb.091751.

Grissom, N., Bhatnagar, S., 2009. Habituation to repeated stress: Get used to it. Neurobiol. Learn. Mem. 92, 215-224. doi:10.1016/j.nlm.2008.07.001.

Herman, J.P., 2013. Neural control of chronic stress adaptation. Front. Behav. Neurosci. 7, 61. doi:10.3389/fnbeh.2013.00061.

Hostetler, C.M., Ryabinin, A.E., 2013. The CRF system and social behavior: a review. Front.Neurosci. 7, 92. doi:10.3389/fnins.2013.00092. 
Huising, M.O., van der Aa, L.M., Metz J.R., de Fatima Mazon. A., Kemenade, B.M., Flik, G., 2007. Corticotropin- releasing factor (CRF) and CRF-binding protein expression in and release from the head kidney of common carp: evolutionary conservation of the adrenal CRF system. J Endocrinol. 193, 349-357. doi:10.1677/JOE-07-0070.

Infante, C., Matsuoka, M.P., Asensio, E., Cañavate, J.P., Reith, M., Manchado, M., 2008. Selection of housekeeping genes for gene expression studies in larvae from flatfish using real-time PCR. BMC Mol. Biol. 9, 28.

Jentoft, S., Aastveit, A.H., Torjesen, P.A., Andersen, Ø., 2005. Effects of stress on growth, cortisol and glucose levels in non-domesticated Eurasian perch (Perca fluviatilis) and domesticated rainbow trout (Oncorhynchus mykiss). Comp. Biochem. Physiol. - A Mol. Integr. Physiol. 141, 353-358. doi:10.1016/j.cbpb.2005.06.006.

Johansen, I.B., Sørensen, C., Sandvik, G.K., Nilsson, G.E., Höglund, E., Bakken, M., Overli, O., 2012. Neural plasticity is affected by stress and heritable variation in stress coping style. Comp Biochem Physiol Part D Genomics Proteomics.7(2), 161-71. doi: 10.1016/j.cbd.2012.01.002.

Johansson, K., Sigray, P., Backström, T., Magnhagen, C., 2016. Stress Response and habituation to motorboat noise in two coastal fish species in the Bothnian Sea. In The effects of noise on aquatic life II, 513-521. doi: 10.1007/978-1-4939-2981-8_62.

Koakoski, G., Kreutz, L.C., Fagundes, M., Oliveira, T.A., Ferreira, D., da Rosa, J.G.S., Barcellos, L.J.G., 2013. Repeated stressors do not provoke habituation or accumulation of the stress response in the catfish Rhamdia quelen. Neotrop. Ichthyol. 11, 453-457. doi:10.1590/S1679. 62252013005000010.

Lankford, S.E., Adams, T.E., Cech Jr, J.J., 2003. Time of day and water temperature modify the physiological stress response in green sturgeon, Acipenser medirostris. Comp. Biochem. Physiol. A 135, 291-302. doi: 10.1016/S1095-6433(03)00075-8.

Lim, J.E., Porteus, C.S., Bernier, N.J., 2013. Serotonin directly stimulates cortisol secretion from the interrenals in goldfish. Gen. Comp. Endocrinol. 192, 246-255. doi: 10.1016/j.ygcen.2013.08.008

López-Olmeda, J.F., Blanco-Vives, B., Pujante, I.M., Wunderink, Y.S., Mancera, J.M., SánchezVázquez, F.J., 2013. Daily rhythms in the hypothalamus-pituitary-interrenal axis and acute 
stress responses in a teleost flatfish, Solea senegalensis. Chronobiol. Int. 30, 530-539. doi:10.3109/07420528.2012.754448.

López-Patiño, M.A., Conde-Sieira, M., Gesto, M., Librán-Pérez, Soengas, J.L., Míguez, J.M., 2013. Melatonin partially minimizes the adverse stress effects in Senegalese sole (Solea senegalensis). Aquaculture 388-391, 165-172. doi:10.1016/j.aquaculture.2013.01.023.

Madaro, A., Fernö, A., Kristiansen, T.S., Olsen, R.E. rik, Gorissen, M., Flik, G., Nilsson, J., 2016 a. Effect of predictability on the stress response to chasing in Atlantic salmon (Salmo salar L.) parr. Physiol. Behav. 153, 1-6. doi:10.1016/j.physbeh.2015.10.002.

Madaro, A., Olsen, R.E., Kristiansen, T.S., Ebbesson, L.O.E., Flik, G., Gorissen, M., 2016b. A comparative study of the response to repeated chasing stress in Atlantic salmon (Salmo salar L.) parr and post-smolts. Comp. Biochem. Physiol. A. Mol. Integr. Physiol. 192, 7-16. doi:10.1016/j.cbpa.2015.11.005.

Manuel, R., Metz, J.R., Flik, G., Vale, W.W., Huising, M.O., 2014a. Corticotropin-releasing factorbinding protein (CRF-BP) inhibits CRF- and urotensin-I-mediated activation of CRF receptor-1 and -2 in common carp. Gen. Comp. Endocrinol. 202, 69-75. doi: 10.1016/j.ygcen.2014.04.010.

Manuel, R., Gorissen, M., Roca, C.P., Zethof, J., van de Vis, H., Flik,G., van den Bos, R., $2014 b$. Inhibitory avoidance learning in zebrafish (Danio rerio): effects of shock intensity and unraveling differences in task performance. Zebrafish 11,341-352. doi:10.1089/zeb.2013.0970.

Manuel, R., Boerrigter, J.G.J., Cloosterman, M., Gorissen, M., Flik, G., van den Bos, R., van de Vis, H. 2016. Effects of acute stress on aggression and the cortisol response in the African sharptooth catfish Clarias gariepinus: differences between day and night. J. Fish Biol. 88, 21752187. doi:10.1111/jfb.12989.

McCarty, R., 2016. Learning about stress: neural, endocrine and behavioral adaptations. Stress Vol. 19 , Iss. 5. doi: 10.1080/10253890.2016.1192120.

Mendonça, P.C., Gamperl, A.K., 2009. Nervous and humoral control of cardiac performance in the winter flounder (Pleuronectes americanus). J. Exp. Biol. 212, 934-944. doi:10.1242/jeb.027680.

Milligan, C. L., Wood, C.M., 1987. Regulation of blood oxygen transport and red cell pHi after exhaustive activity in rainbow trout (Salmo gairdneri) and starry flounder (Platichthys stellatus). J. Exp. Biol. 133, 263-282. 
Mugnier, C., Fostier, A., Guezou, S., Gaignon, J.L., Quemener, L., 1998. Effect of some repetitive factors on turbot stress response. Aquac. Int. 6, 33-45. doi:10.1023/a:1009217719227.

Nesse, R.M., Bhatnagar, S., Young, E.A., 2010. Evolutionary origins and functions of the stress response, in Encyclopedia of Stress, 965-970. doi:10.1016/B978-012373947-6.00150-1.

Nilsson, J., Stien, L.H., Fosseidengen, J.E., Olsen, R.E., Kristiansen, T.S., 2012. From fright to anticipation:reward conditioning versus habituation to a moving dip net in farmed Atlantic cod (Gadus morhua). Appl. Anim. Behav. Sci. 138, 118-124. doi:10.1016/j.applanim.2012.02.014.

Noakes, D.L.G., Jones, K.M.M., 2016. Cognition, learning and behavior. In Biology of stress in fish, Fish Physiology, Vol.35, 333-364. https://doi.org/10.1016/B978-0-12-802728-8.00009-6.

Oliveira, C.C.V, Aparício, R., Blanco-Vives, B., Chereguini, O., Martín, I., Javier SánchezVazquez, F., 2013. Endocrine (plasma cortisol and glucose) and behavioral (locomotor and selffeeding activity) circadian rhythms in Senegalese sole (Solea senegalensis Kaup 1858) exposed to light/dark cycles or constant light. Fish Physiol. Biochem. 39, 479-487. doi:10.1007/s10695012-9713-2.

Øverli, Ø., Pottinger, T.G., Carrick, T.R., Øverli, E., Winberg, S., 2001. Brain monoaminergic activity in rainbow trout selected for high and low stress responsiveness. Brain. Behav. Evol. 57, 214-224. doi:10.1159/000047238.

Pfaffl, M.W., 2001. A new mathematical model for relative quantification in real-time RT-PCR. Nucleic Acids Res. 29, e45. doi:10.1093/nar/29.9.e45.

Pinnock, S.B., Herbert, J., 2001. Corticosterone differentially modulates expression of corticotropin releasing factor and arginine vasopressin mRNA in the hypothalamic paraventricular nucleus following either acute or repeated restraint stress. Eur J Neurosci. 13(3), 576-584. doi: 10.3389/fnbeh.2013.00061.

Rose, J.K., Rankin, C.H., 2001. Analyses of habituation in Caenorhabditis elegans. Learn. Mem. 8(2), 63-69. doi:10.1101/lm.37801.so.

Sangiao-Alvarellos, S., Guzmán, J.M., Laíz-Carrión, R., Míguez, J.M., Martín del Río, M.P., Mancera, J.M., Soengas, J.L., 2005. Interactive effects of high stocking density and food deprivation on carbohydrate metabolism in several tissues of gilthead sea bream Sparus auratus. J. Exp. Zool. 303A, 761-775. doi: 10.1002/jez.a.203. 
Smith, P.K., Krohn, R.I., Hermanson, G.T., Mallia, A.K., Gartner, F.H., Provenzano, M.D., Fujimoto, E.K., Goeke, N.M., Olson, B.J., Klenk, D.C., 1985. Measurement of protein using bicinchoninic acid. Anal. Biochem. 150, 76-85. doi:10.1016/0003-2697(85)90442-7.

Sørensen, C., Johansen, I.B., Øverli, Ø., 2013. Neural plasticity and stress coping in teleost fishes. Gen Comp Endocrinol. 181, 25-34. doi: 10.1016/j.ygcen.2012.12.003.

Summers $\mathrm{CH}$, Winberg S., 2006. Interactions between the neural regulation of stress and aggression. J Exp Biol. 209, 4581-4589.

Van Ham, E.H., Van Anholt, R.D., Kruitwagen, G., Imsland, A.K., Foss, A., Sveinsbø, B.O., FitzGerald, L.; Parpoura, A.C., Stefansson, S.O., Bonga, S.E., 2003. Environment affects stress in exercised turbot. Comp. Biochem. Physiol. - A Mol. Integr. Physiol. 136, 525-538. doi:10.1016/S1095-6433(03)00083-7.

Viblanc, V.A., Smith, A.D., Gineste, B., Groscolas, R., 2012. Coping with continuous human disturbance in the wild: insights from penguin heart rate response to various stressors. BMC Ecol. 12, 10. doi:10.1186/1472-6785-12-10.

Vijayan, M.M., Ballantyne, J.S., Leatherland, J.F., 1990. High stocking density alters the energy metabolism of brook charr, Salvelinus fontinalis. Aquaculture 88, 371-381. doi: 10.1016/00448486(90)90162-G.

Weber, R.A., MacEira, J.J.P., Mancebo, M.J., Peleteiro, J.B., Martín, L.O.G., Aldegunde, M., 2012. Effects of acute exposure to exogenous ammonia on cerebral monoaminergic neurotransmitters in juvenile Solea senegalensis. Ecotoxicology 21, 362-369. doi:10.1007/s10646-011-0797-8.

Wendelaar Bonga, S., 1997. The stress response in fish. Physiol. Rev. 77, 591-625. Available at: http://physrev.physiology.org/content/77/3/591.short.

Winberg, S., Nilsson, G.E., 1993. Roles of brain monoamine neurotransmitters in agonistic behaviour and stress reactions, with particular reference to fish. Comp. Biochem. Physiol. Part C Comp. 106, 597-614. doi:10.1016/0742-8413(93)90216-8.

Wunderink, Y.S., Engels, S., Halm, S., Yúfera, M., Martínez-Rodríguez, G., Flik, G., Klaren, P.H., Mancera, J.M., 2011. Chronic and acute stress responses in Senegalese sole (Solea senegalensis): The involvement of cortisol, CRH and CRH-BP. Gen. Comp. Endocrinol. 171, 203-210. doi:10.1016/j.ygcen.2011.01.010. 
Table 1

Nucleotide sequences of the PCR primers used to evaluate mRNA abundance by qPCR.

\begin{tabular}{llll}
\hline & Forward primer & Reverse primer & $\begin{array}{l}\text { Accession } \\
\text { number }\end{array}$ \\
\hline$u b q$ & AGCTGGCCCAGAAATATAACTGCGACA & ACTTCTTCTTGCGGCAGTTGACAGCAC & CAB291588 \\
$c r h$ & CCTGACCTTCCACCTGCTAC & GAGATCTTTGGCGGAGTGAA & FR745427 \\
$c r h b p$ & GGCAATGGCATAGACACCTC & CACTGGACACCAGCCTCAC & FR745428 \\
\hline
\end{tabular}

ubq: ubiquitine; $c r h$ : corticotropine released hormone; crhbp: corticotropine released hormone binding protein 


\section{Figure captions}

Figure 1. Scheme of the experimental design showing the chasing protocols applied to each of the experimental groups.

Figure 2. Plasma levels of cortisol, glucose and lactate in Senegalese sole not exposed (control; black bar), single exposed (ST/naïve; striped bar) or reiterative exposed (white bars; during the day $\mathrm{ST} / \mathrm{Dt}$, the night ST/Nt or both ST/Dt+Nt) to handling stress. Bars represent the mean $\pm \mathrm{SEM}$ $(\mathrm{n}=10)$. Different letters indicate differences among the experimental groups $(\mathrm{P}<0.05)$.

Figure 3. Plasma levels of adrenaline and noradrenaline in Senegalese sole not exposed (control; black bar), single exposed (ST/naïve; striped bar) or reiterative exposed (white bars; during the day $\mathrm{ST} / \mathrm{Dt}$, the night $\mathrm{ST} / \mathrm{Nt}$ or both $\mathrm{ST} / \mathrm{Dt}+\mathrm{Nt}$ ) to handling stress. Bars represent the mean $\pm \mathrm{SEM}$ $(n=10)$. Different letters indicate differences among the experimental groups $(\mathrm{P}<0.05)$.

Figure 4. Hepatic levels of glucose, glycogen and lactate in Senegalese sole not exposed (control; black bar), single exposed (ST/naïve; striped bar) or reiterative exposed (white bars; during the day $\mathrm{ST} / \mathrm{Dt}$, the night ST/Nt or both ST/Dt+Nt) to handling stress. Bars represent the mean $\pm \mathrm{SEM}$ $(\mathrm{n}=10)$. Different letters indicate differences among the experimental groups $(\mathrm{P}<0.05)$.

Figure 5. Levels of dopamine (DA), 3,4-dihydroxyphenylacetic acid (DOPAC) and dopaminergic ratio and 5-hydroxytryptophan (5HTP), serotonin (5HT), 5-hydroxyindoleacetic acid (5HIAA) and serotonergic ratio in the hypothalamus of Senegalese sole not exposed (control; black bar), single exposed (ST/naïve; striped bar) or reiterative exposed (white bars; during the day ST/Dt, the night $\mathrm{ST} / \mathrm{Nt}$ or both $\mathrm{ST} / \mathrm{Dt}+\mathrm{Nt})$ to handling stress. Bars represent the mean $\pm \mathrm{SEM}(\mathrm{n}=10)$. Different letters indicate differences among the experimental groups $(\mathrm{P}<0.05)$.

Figure 6. Levels of dopamine (DA), 3,4-dihydroxyphenylacetic acid (DOPAC) and dopaminergic ratio and 5-hydroxytryptophan (5HTP), serotonin (5HT), 5-hydroxyindoleacetic acid (5HIAA) and serotonergic ratio in the telencephalon of Senegalese sole not exposed (control; black bar), single exposed (ST/naïve; striped bar) or reiterative exposed (white bars; during the day ST/Dt, the night $\mathrm{ST} / \mathrm{Nt}$ or both $\mathrm{ST} / \mathrm{Dt}+\mathrm{Nt})$ to handling stress. Bars represent the mean $\pm \mathrm{SEM}(\mathrm{n}=10)$. Different letters indicate differences among the experimental groups $(\mathrm{P}<0.05)$.

Figure 7. Levels of mRNA of $c r h$ and $c r h b$ in the hypothalamus of Senegalese sole not exposed (control; black bar), single exposed (ST/naïve; striped bar) or reiterative exposed (white bars; during the day ST/Dt, the night ST/Nt or both ST/Dt+Nt) to handling stress. Bars represent the 
mean \pm SEM $(n=10)$. Different letters indicate differences among the experimental groups $(\mathrm{P}<$ $0.05)$. 
Highlights:

- Handling stress may result in productivity losses in aquaculture.

- Animals can sometimes habituate to a reiterative stressor by reducing the physiological response that such stressor evoked initially.

- Solea senegalensis is an interesting species in European aquaculture and the knowledge regarding potential stressors and the species stress habituation is still limited.

- Parameters related to the physiological stress response are evaluated in plasma and brain to obtain information regarding the overall status of animal after stress exposure.

- Results suggest that there is not a habituation to repeated acute stress in Solea senegalensis, although a possible modulation of the stress response occurs in trained fish. 
Repeated stress events

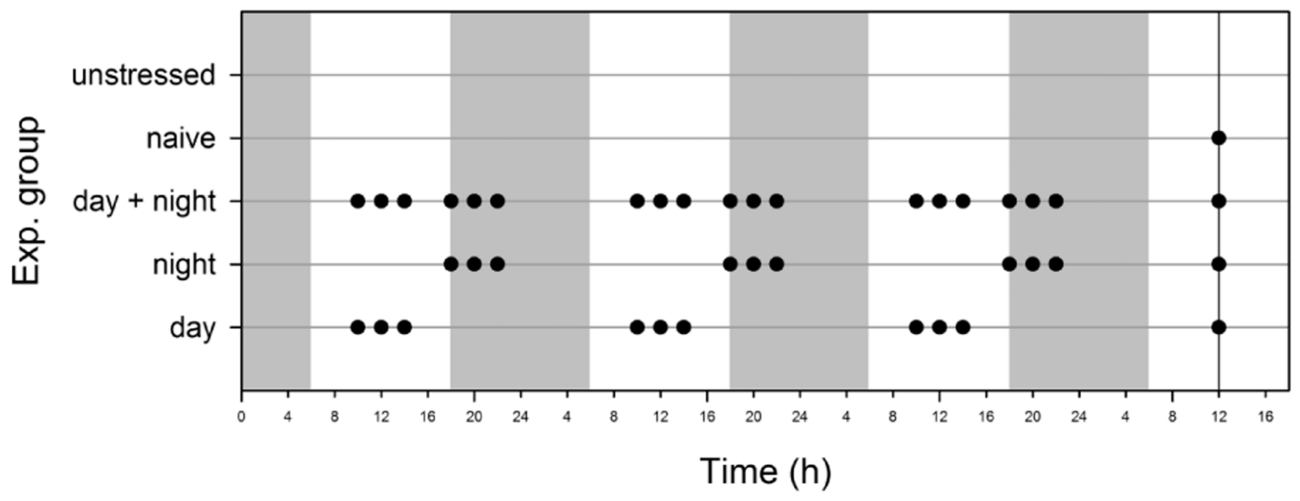

Figure 1 

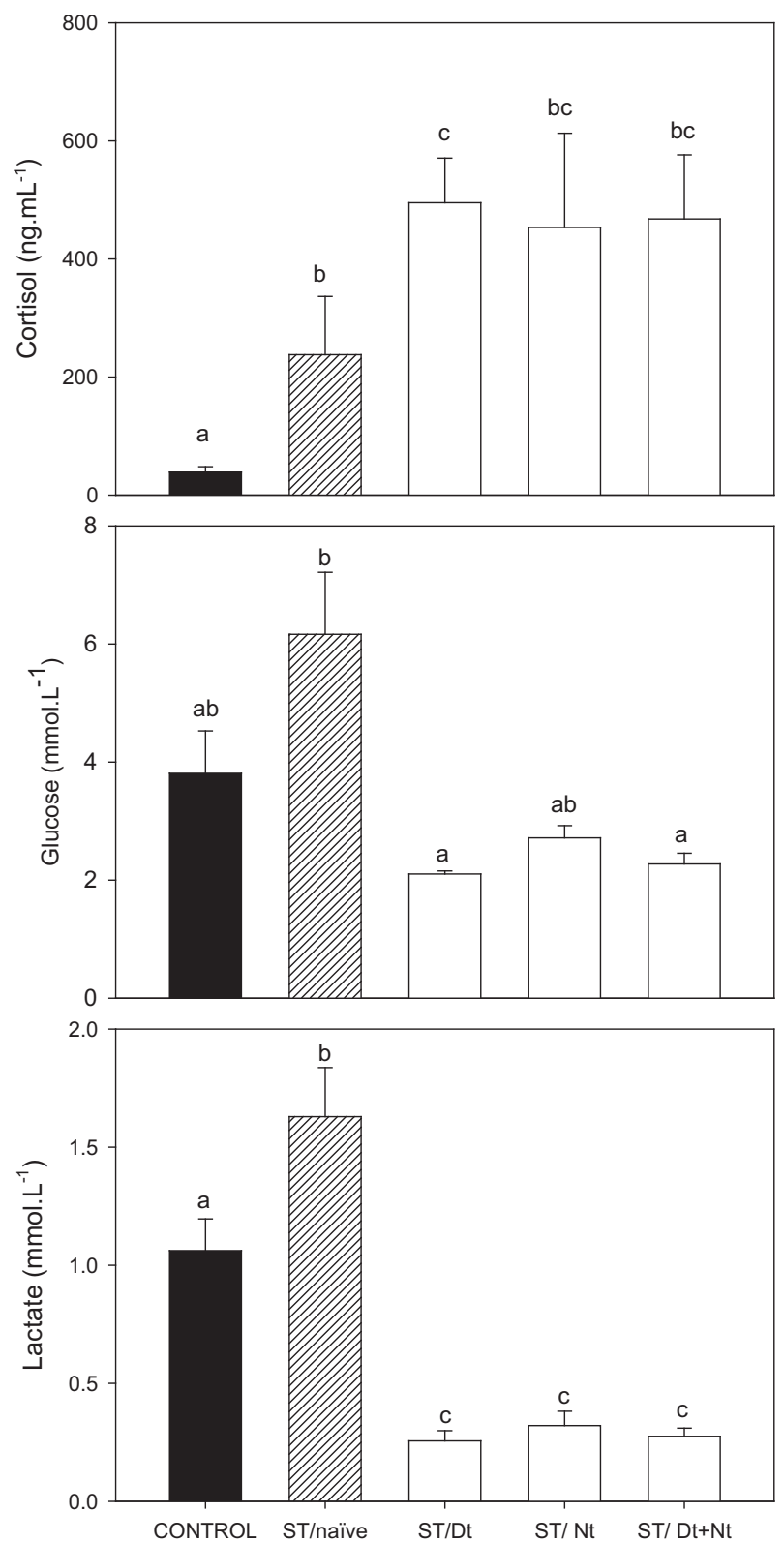

Figure 2 

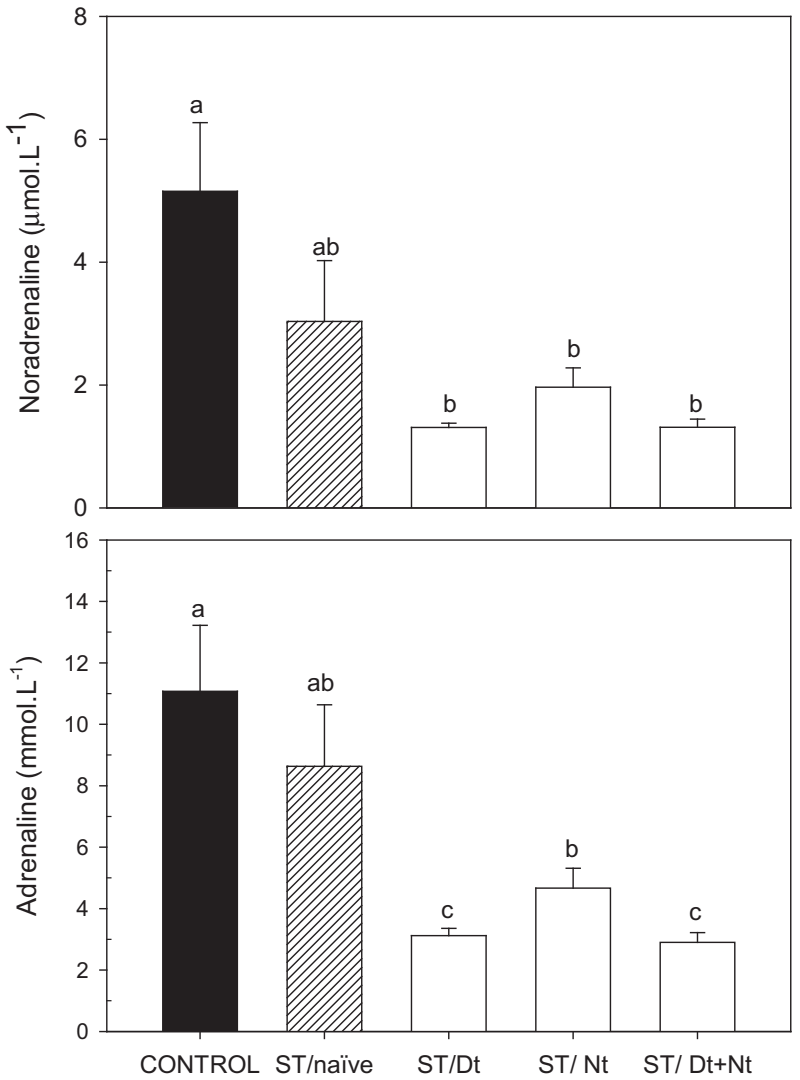

Figure 3 

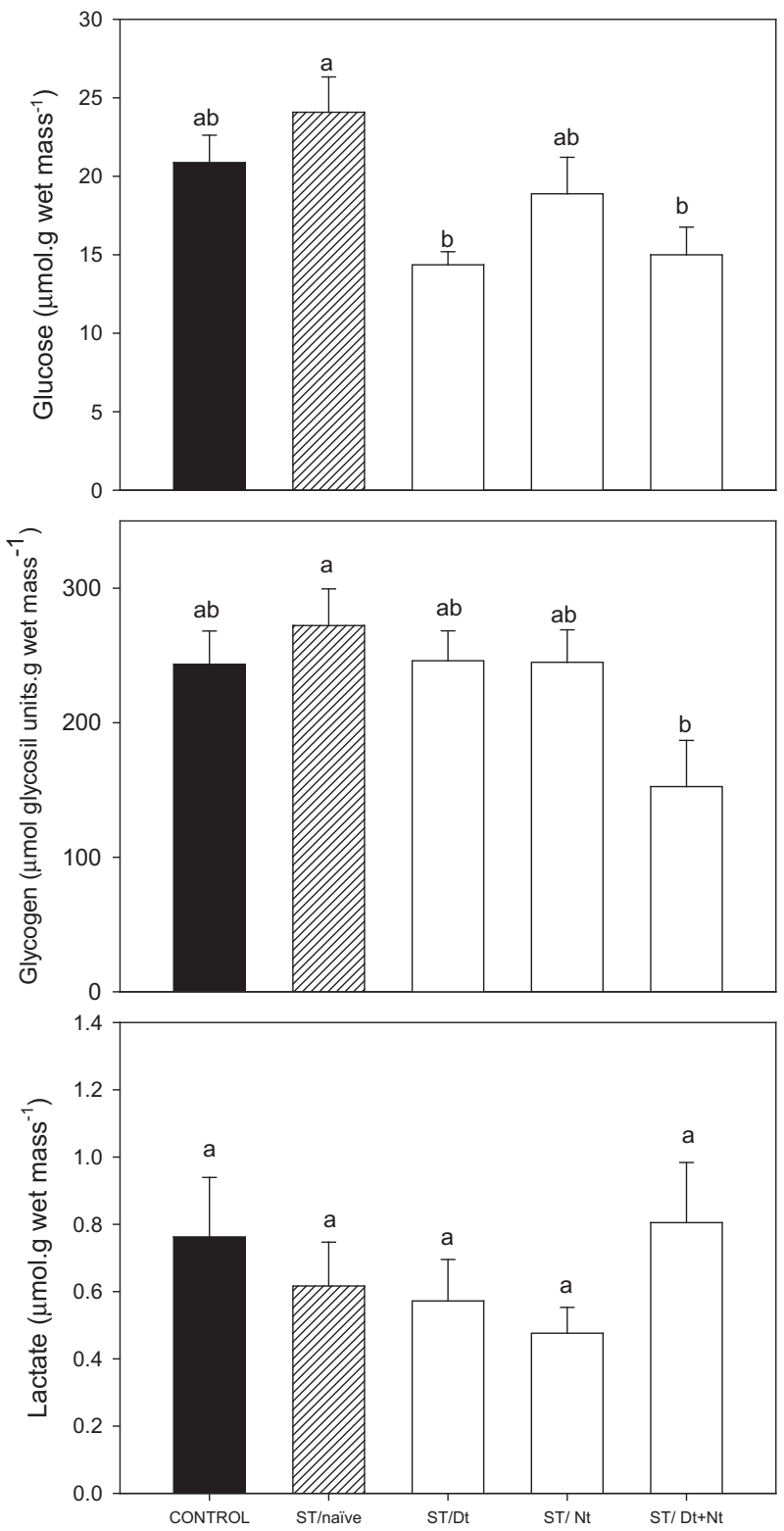

Figure 4 

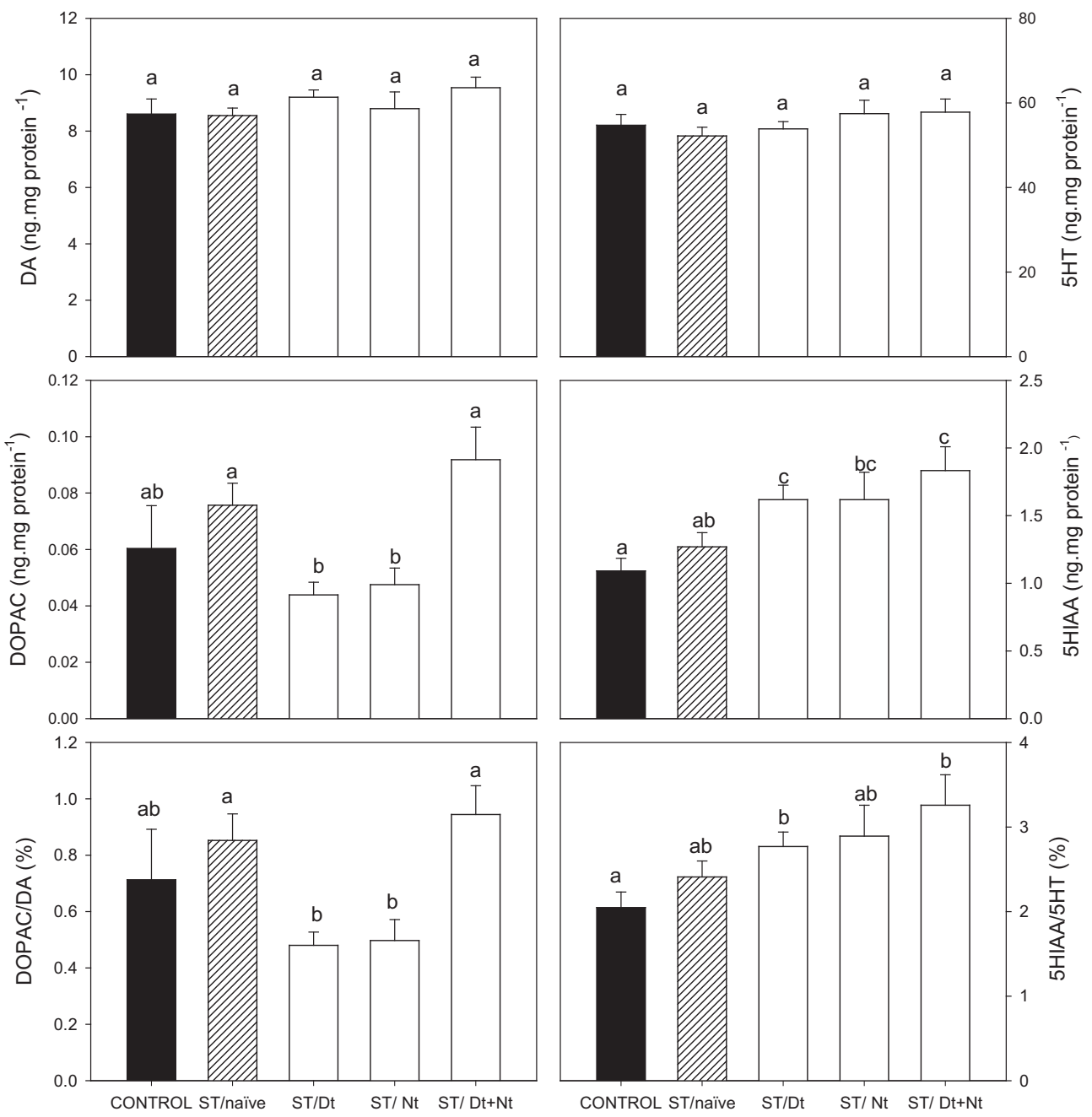

Figure 5 

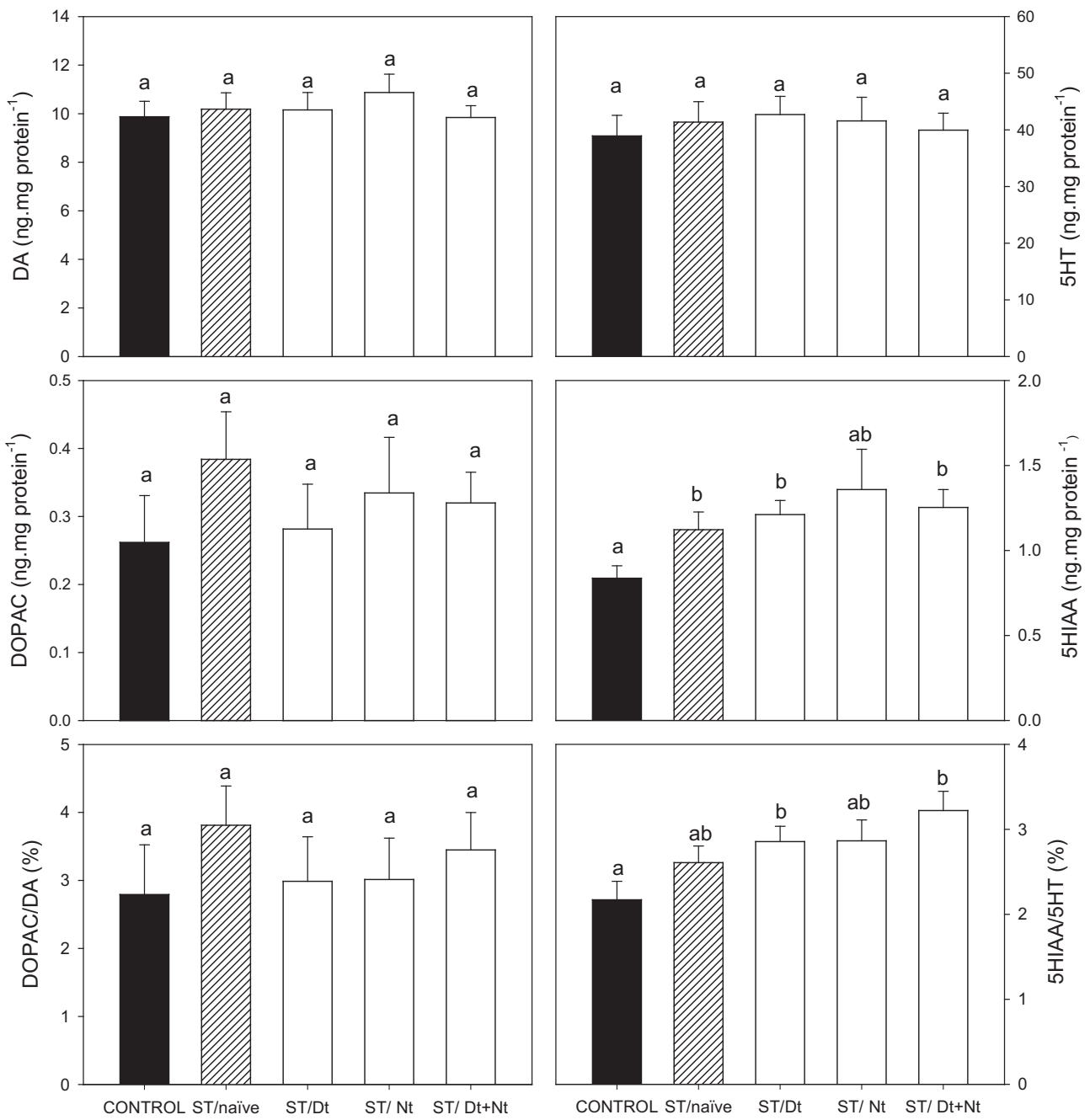

Figure 6 

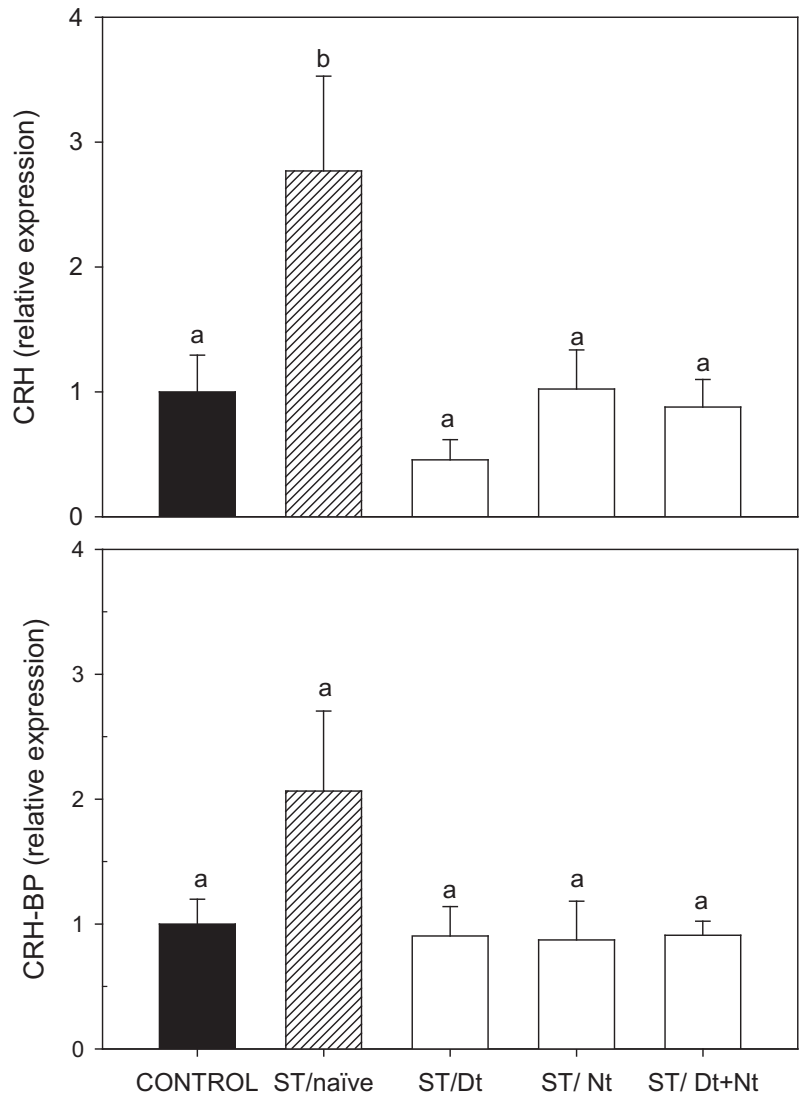

Figure 7 